\title{
EXPERIMENTAL STUDY OF WINDOW SHADING EFFECT ON BUILDING THERMAL-VISUAL COMFORT IN A TROPICAL REGION
}

\author{
*Remon Lapisa ${ }^{1,2}$, Arwizet Karudin ${ }^{1,2}$, Krismadinata ${ }^{1,2}$ and Ambiyar ${ }^{1}$ \\ ${ }^{1}$ Faculty of Engineering, Universitas Negeri Padang, Indonesia \\ ${ }^{2}$ Centre for Energy and Power Electronics Research (CEPER), Universitas Negeri Padang, Indonesia
}

*Corresponding Author, Received: 14 Sept. 2021, Revised: 23 Sept. 2021, Accepted: 03 Oct. 2021

\begin{abstract}
Thermal-visual comfort are important aspects of building design. Indoor thermal and daylight conditions in buildings are strongly affected by the amount of solar heat gain transmitted by windows. This experimental study aims to analyze the impact of window internal shading on the thermal-visual comfort of a residential building. The measurement is carried out on two building prototypes with a size of $80 \mathrm{~cm} \times 60 \mathrm{~cm}$ and a height of $50 \mathrm{~cm}$. The building roof is made of zinc-coated steel with a $30^{\circ}$ - degree slope. The walls of the prototypes are $9 \mathrm{~mm}$ thick plywood boards. $40 \mathrm{~cm} \times 30 \mathrm{~cm}$ glass windows are installed on the front and backside of the building. Thermal and visual effects of windows are analyzed by comparing the indoor temperature and daylight illuminance for two cases; building with and without shading devices. Indoor temperature and daylight illuminance are measured for three different degrees of slat angles of shading device; (a) $90^{\circ}$ (vertical slat position, no solar irradiation enter in the room), (b) $45^{\circ}$, and (c) $0^{\circ}$ (horizontal slat position). The measurement results shows that the change in the angle of the shading slats affects the thermal-visual conditions of the room.
\end{abstract}

Keywords: Window-internal shading, Indoor temperature, Thermal comfort, Visual comfort, Tropical region

\section{INTRODUCTION}

Besides the economic and safety aspects, the thermal and visual comfort are other crucial aspects that need to be considered in a sustainable building design $[1,2]$. Building with thermal and visual comfort will influence the physical and psychological condition as well as the behavior, and productivity of the occupants [3, 4]. Moreover, a building that cannot provide adequate comfort has the potential to cause unfavorable impacts on occupants, such as health problems and decreased productivity [5]. To ensure the buildings have required thermal-visual comfort, they are often equipped with some technical devices such as heating and cooling for air conditioning, artificial lighting systems [6-9] and ventilation for interior air quality [10]. However, the installation of these devices adds several disadvantages such as additional building costs (installation, operation, maintenance), notable energy consumption [11] and environmental impact [12]. In fact, passive cooling techniques can be used as alternative solutions to increase the building thermal-visual comfort while saving energy consumption. The implementation of passive cooling techniques in increasing building thermal-visual comfort have been performed in some previous studies [13-18]. Meanwhile, for outdoor thermal comfort improvement, some strategies can be performed such as urban greening, cool pavements, landscape arrangement [19-21]

In terms of energy and environmental aspects, the building sector consumes $40 \%$ of the world's energy needs [22] and emits up to $23 \%$ of greenhouse gas emissions [23]. Of the building's energy consumption, more than $50 \%$ is used for heating, ventilation, and air conditioning systems [24]. Another study related to lighting systems in office buildings shows that $26 \%$ of the total energy consumption of buildings in Indonesia is for lighting system [25]. Therefore, it is necessary to save electricity energy consumption, especially for lighting systems using natural lighting. Optimizing natural lighting by setting the windows (surface, opening scenario) helps reduce electrical energy consumption and increases thermal comfort [2, 26]. Several studies suggest that the optimal use of natural lighting can provide visual comfort for occupants and reduce environmental impacts [27, 28]. Moreover, the energy efficiency by using passive techniques (natural ventilation, daylighting) is actually able to increase Indonesian national energy security and to preserve the environment [29].

Daylight for conventional residential building is usually obtained through windows or glass doors installed on the wall [30]. However, direct solar radiation that enters through the transparent surface of the window can cause an increase in the indoor air temperature [31]. Therefore, implementing a 
strategy to regulate solar radiation to obtain maximum lighting with minimal overheating impact is necessary. One of the devices in controlling the radiation and lighting intensity is a shading device [32]. Shading can be installed on the inside or outside of the window glass [33]. Shading device performance depends on several aspects, including shading material and slat shading angle [34]. Several studies have shown that the installation of shading devices increases $20.5 \%$ of the energy efficiency of a building [35].

This study aims to analyze the impact of the slat angle of a Venetian blind shading on indoor air temperature and daylighting levels. Three cases of blind slat angle analyzed in this study are; (a) case1: $90^{\circ}$ angle (vertical blind slat position, no solar radiation enters the room), (b) case-2: $45^{0}$ angle downward toward the window, and (c) case-3: $0^{0}$ angle (horizontal blind slat position). Experimental study and data collection is carried out in Padang city-Indonesia, within three days in a row with a set angle variation. The research methodology and results can assist homeowners in maximizing natural lighting to obtain optimal thermal and lighting comfort by adjusting the angle of the slat of internal shading device

\section{RESEARCH SIGNIFICANCE}

Transmission of direct solar radiation into the room through glass windows will significantly affect the level of day lighting and thermal conditions of the building space. For tropical region, to control indoor solar heat gain buildings are often equipped with window shading. Therefore it is necessary to determine the optimal fraction of windows shaded to maximize indoor day lighting by considering the room temperature and building thermal comfort. The results of this study can be used as a benchmark to control the window shading fraction in the tropics.

\section{SUN CONTROL AND SHADING DEVICES}

The main reason for installing shading devices on windows is to control the amount of direct sunlight that enters the room. In equatorial regions with hot-humid climates such as in Indonesia, solar gain can cause a significant increase in room temperature and reduce thermal comfort. If the room is equipped with a cooling system, the solar gain causes an increase in energy consumption for air conditioning. Reduction of direct solar radiation by installing shading devices on windows can significantly reduce cooling requirements or can improve indoor thermal comfort in a notconditioned room. However, the installation of shading devices has the risk of lowering the daylighting level of the room, causing additional energy for artificial lighting [36]. Internal windows shading can prevent unwanted direct solar radiation.

Solar radiation that enters the building can be naturally blocked by several objects around it, such as hills (natural landscape), trees, neighboring buildings, parts of the building itself (overhangs, awnings, trellises). Under certain conditions, building windows are installed with opaque materials called shading devices. Window shading devices are needed to control the penetration of solar radiation into the room [37]. The shading material reflects the radiation into the surrounding environment. The effectiveness of reducing the solar gain obtained due to the installation of shading devices is highly dependent on the configuration of the shading geometry, shading material, activation strategy [38]. There are several types of shading devices, including roller shades, vertical folding shading, Venetian blinds [39]. In this study, the type of internal shading is Venetian blind (Fig. 1).

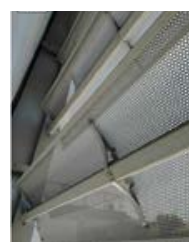

a.

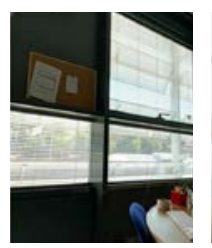

b.

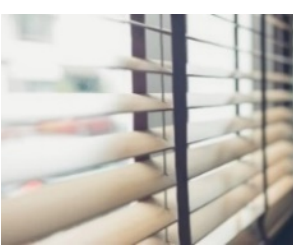

c.
Fig.1 Shading device types: a. internal shading, b. external shading [34] and c.Venetian blind

\section{MATERIAL AND METHOD}

\subsection{Building Prototype Characteristics and Case Study}

This experimental study is conducted on two prototype buildings with $80 \mathrm{~cm}$ in length, $60 \mathrm{~cm}$ in width, and $50 \mathrm{~cm}$ in height (Fig. 2). The roof of the building is made of zinc-coated steel with a roof slope of $30^{\circ}$. The walls are made of GRC board, which has almost the same characteristics as the walls commonly used for buildings in Indonesia. A $40 \mathrm{~cm} \times 30 \mathrm{~cm}$ glass window is installed on the front facade wall. The window type is single glass with a solar transmission factor of 0.7. Building walls with windows facing south can reduce the entry of solar radiation into the room through the windows.

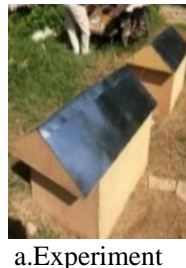

site

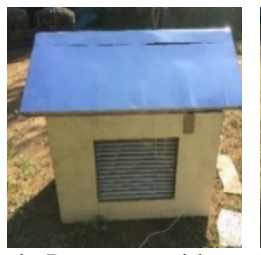

b. Prototype with shading

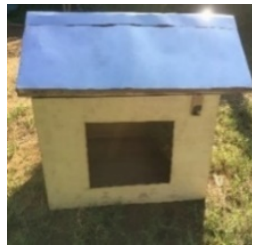

b.Prototype without shading
Fig.2 Building prototype and experiment location 
Inside the first building window (prototype-1), Venetian blind shading with adjustable slat angle is installed. The windows of other building are left without internal shading devices to maximize the entry of solar radiation for natural lighting. In this study, the indoor temperature and the intensity of natural lighting in the room are measured on three consecutive days. It was done on three different slat shading angle cases; Case-1: $90^{\circ}$ angle (upright shading slat position, no solar irradiation enter in the room), Case-2: $45^{0}$ angle, (slope angle of $45^{0}$ to the horizontal line), and Case-3: $0^{0}$ angle (horizontal shading slat position) (see Fig. 3). The experiment is carried out in an open space in the city of Padang. The temperature and illuminance are measured and recorded. The experiment location is free from shadows of other objects around the prototype (Fig. 2).

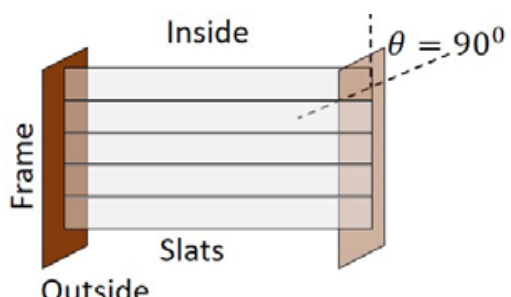

a. Case 1

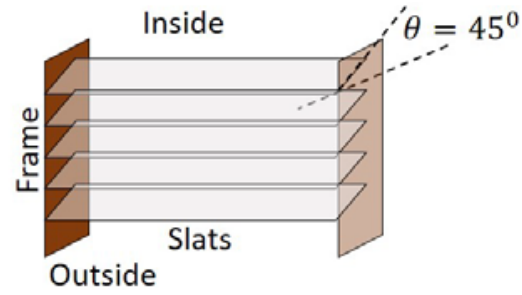

b. Case 2

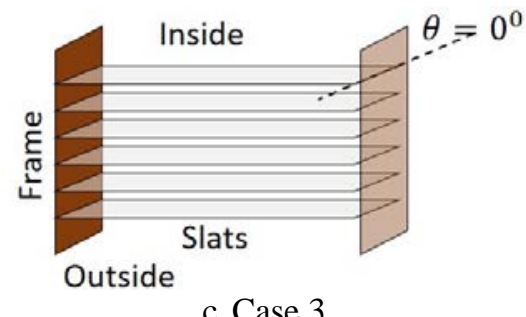

Fig.3 The different case for the angle of shading slat: a. $90^{\circ}$ (vertical slats position), b. $45^{\circ}$ and c. $0^{0}$ (horizontal slats position)

In this study, indoor temperature is measured using the S220-T8 handheld thermocouple data logger. The temperature sensor uses a type $\mathrm{K}$ thermocouple which can measure temperatures in the range of $-200{ }^{0} \mathrm{C}$ to $1800{ }^{0} \mathrm{C}$ with $0.1{ }^{0} \mathrm{C}$ resolution. The thermocouple temperature measurement accuracy is $1-5 \%$. The sensor is placed in the interior of the room that is protected from direct solar radiation. While the level of daylighting in the room is measured using a multifunction environment meter CEM DT-8820 with an accuracy of $0.3 \%$. Experimental data retrieval is carried out from 8 am to $5 \mathrm{pm}$. The data are recorded every 10 minutes. The measurement of the daylighting level is taken at five different times of the day; at 8 am, 10 am, 12 pm, 2 pm, and 4 pm.

\subsection{Climate Characteristics of Loacation}

Padang city (0.949 S and $100.35 \mathrm{E}$ ) is in the western part of Indonesia, which is directly adjacent to the Indian Ocean (Fig. 4). According to the Köppen Climate Classification, the climate in Padang is hot and humid and receives constant solar radiation throughout the year [40]. The annual mean air temperature and humidity in Indonesia are around $28{ }^{\circ} \mathrm{C}$ and $78 \%$, consecutively [41]. The outdoor temperature can reach a maximum value of $34.1{ }^{0} \mathrm{C}$ [8]. With a tropical climatic condition, thermal comfort in Padang is a crucial thing to consider in the concept of a residential building. The average intensity of solar radiation at this location was around $386.5 \mathrm{~W} / \mathrm{m}^{2}$ with a maximum value of up to $1055 \mathrm{~W} / \mathrm{m}^{2}$ [8]. The high intensity of solar radiation may cause thermal discomfort in the room, especially during the day.

The maximum outdoor global illuminance in the tropical region is between 14,350 to 100,000 lux [42, 43] when the sky is clear without a cloud. This illuminance value significantly decreases if the sky is cloudy (overcast sky). At this time, the value may reach 10,000 lux [44, 45]. Meanwhile, at night, the illuminance level drops drastically to less than 3 lux $[46,47]$. The outdoor illuminance level is also influenced by the geographical contours and the density of the building location. Some objects around the building can affect the local illuminance level due to shadows from mountains/hills, neighboring buildings, trees, etc. In this study, measurements of temperature and lighting levels asre carried out in an open space so that both prototypes could receive direct solar radiation (Fig. 4.b).
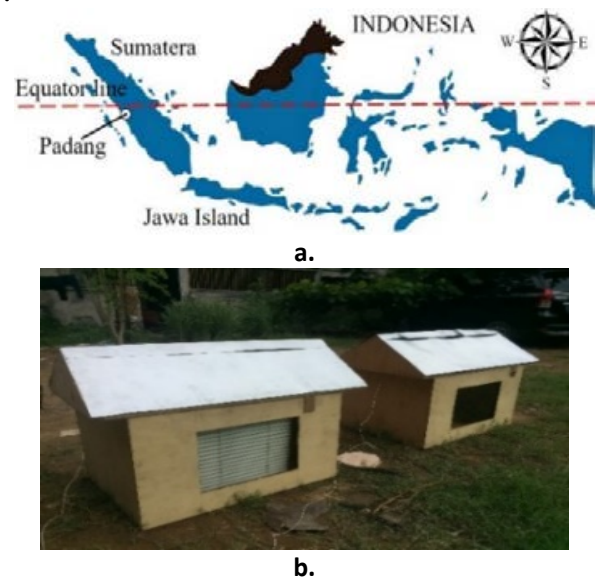

Fig. 4 a. Location of Padang city, b. Site condition of experiment 


\section{RESULTS AND DISCUSSION}

\subsection{Effect of Shading Device on Indoor Temperature and Thermal Comfort}

To determine the effect of Venetian blinds as shading devices on the changes in indoor temperature and comfort, a comparison of the temperatures between prototypes with and without shading devices installed is conducted. In the first part of the analysis, the slats of the Venetian blinds are tightly closed with a slat of $90^{\circ}$ angles to the horizontal line. At this angle, the most direct solar radiation that hits the window will be blocked and reflected by the slat-shading surface.

Temperature sampling is carried out on three consecutive days, with identical environmental conditions for both prototypes. The two prototypes were placed close together in an open space exposed to direct sunlight. The temperature changes over time for the two prototypes are in Fig. 5. In general, the indoor air temperature for the two-building prototypes shows the same tendency. The room temperature on that day varied with a minimum and maximum limit of $26.2{ }^{0} \mathrm{C}$ and $37.8{ }^{0} \mathrm{C}$, consecutively. Based on the measurement on the first day, the indoor air temperature for the two prototypes increased gradually from early morning to midday. In the morning at 9 a.m., the indoor air temperature on the two prototypes decreased since the sky is partially covered by clouds. The presence of clouds in the sky reduces the direct sunlight hitting the building. For cloudy sky conditions, the thermal gain absorbed by the building envelope only comes from the diffuse radiation reflected by the sky. For both prototypes, the highest indoor temperature occurred at noon at 2 p.m. It is caused by the peak of solar radiation in this hour that illuminates the building and the high exterior air temperature around the building. A few minutes later, the indoor temperature of both prototypes dropped significantly because there were more clouds blocking the sun's direct radiation.

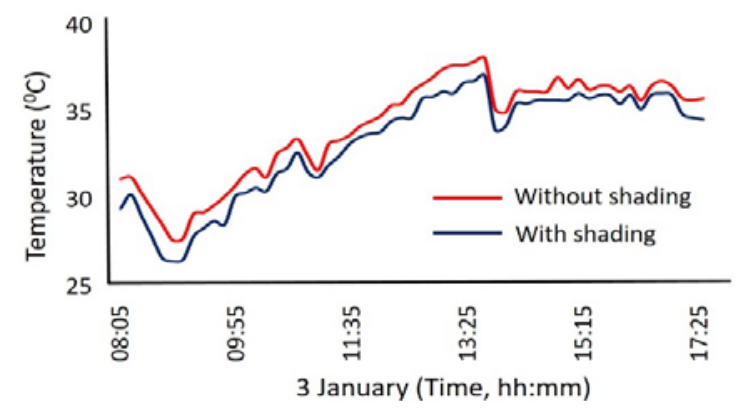

Fig.5 Indoor temperature variation for the Case-1 on the first day of measurement.
The data presented in Fig. 5 shows the significant effect of shading devices on windows. The prototype without shading (red line in the graph), has an indoor temperature that is significantly hotter than the other prototype with a shading device (blue line). In the shading slat position that completely covers the window, direct solar radiation is blocked and does not enter the room. The indoor temperature in the prototype with shading device is consistently lower throughout the day than the reference building without shading. The daily average indoor air temperature of protoype- 1 is $0.94{ }^{\circ} \mathrm{C}$. It is lower than the other prototype due to the reduction in solar thermal gain by shading devices. By blocking the direct sunlight, the shading device makes the room temperature more thermally comfortable. The temperature dropped by $0.94{ }^{0} \mathrm{C}$. It has a very significant impact on occupant thermal comfort and energy consumption efficiency for the air conditioning system. During the measurement time, the maximum decrease in temperature due to the presence of a shading device is $1.9{ }^{0} \mathrm{C}$ during the day when the intensity of solar radiation is high. The higher the intensity of direct solar radiation, the hotter the room temperature. So that the installation of shading devices at the time of peak solar radiation will provide a significant decrease in indoor temperature.

\subsection{Effect of the Slope Angle of Shading Slat}

The next step is to analyze the impact of the shading slat angle on the changes in room temperature. The data are collected in three days with different slope angles of shading slats; $90^{\circ}, 45^{\circ}$, and $0^{0}$. For reference, the windows in prototype- 2 are left without a window-shading device. The effect of the slope angle of the slat shading on changes in interior temperature is shown in Fig 5.

Fig. 6.a and Fig. 6.b show that the installation of a shading device on the window has a significant impact on decreasing room air temperature for both Case slope angles. The air temperature profile on the two prototypes for two days is affected by the outside air temperature conditions and the intensity of solar radiation received by the building. The most significant decrease in temperature occurred during the day between 12 am and 2 pm (Fig. 5 and Fig. 6). It shows that the effectiveness of shading devices in cooling the room temperature becomes significant if the sun has a high radiation intensity. Meanwhile, in the morning and evening, when the intensity of solar radiation is low, the decrease in room temperature due to the shading becomes less significant. 


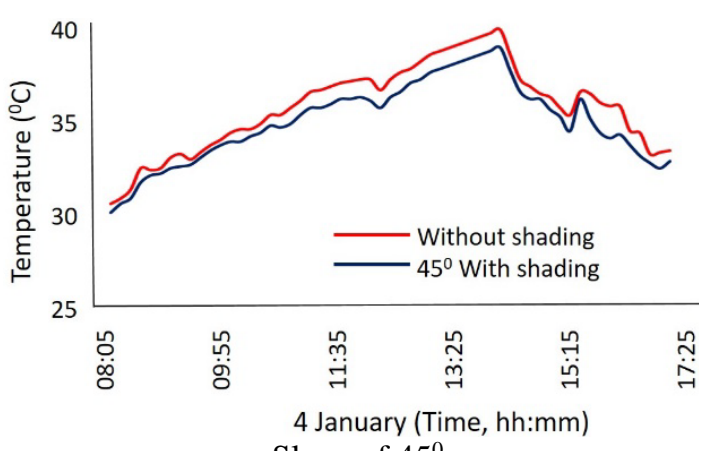

a. Slope of $45^{0}$

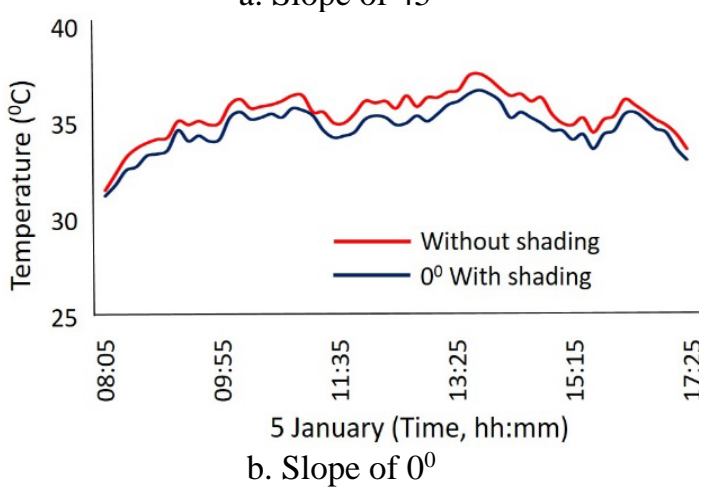

Fig.6 Decrease in temperature due to slope angle of shading slat compared to the prototype without shading

Table 1 Decrease in temperature due to slope angle of shading slat compared to the prototype without shading

\begin{tabular}{lccc}
\hline Decrease in Temperature & \multicolumn{3}{c}{ Slope of shading slat } \\
\cline { 2 - 4 } & $90^{0}$ & $45^{0}$ & $0^{0}$ \\
\hline Average Decrease $\left({ }^{0} \mathrm{C}\right)$ & 0.94 & 0.81 & 0.77 \\
Maximum Decrease $\left({ }^{0} \mathrm{C}\right)$ & 1.9 & 1.8 & 1.5 \\
\hline
\end{tabular}

The decrease in temperature for the two different shading slat angles can be seen in Table 1 . From the three cases of slope angles, it can be seen that the average indoor temperature in Case-1 has the highest decrease (the shading slat is tightly closed), where solar radiation is completely blocked. In Case-1, the maximum indoor air temperature decrease is $1.9{ }^{\circ} \mathrm{C}$ with an average of $0.94{ }^{\circ} \mathrm{C}$. When the shading slat is partially opened (Case-2: slope angle $45^{\circ}$ ), the cooling effect of the average temperature becomes lower by $0.81{ }^{\circ} \mathrm{C}$. The cooling effect of the temperature becomes lower until 0.77 ${ }^{0} \mathrm{C}$ in Case-3 when the shading slat is in a horizontal (open) position. The decrease in the average indoor temperature by $0.77{ }^{\circ} \mathrm{C}-0.94{ }^{\circ} \mathrm{C}$ increases thermal comfort in unconditioned buildings or increases energy consumption efficiency in conditioned buildings. For 8 hours of measurement time, the accumulative decrease in degree hour (DH) is 53.7 ${ }^{0} \mathrm{C}$.h is observed. In fact, a decrease in degree hours over a yearly period can represent energy savings for the air conditioning system. This energy efficiency is an advantage of using shading devices on building windows.

\subsection{Effect of Window Shading on Indoor Illuminance Level}

Not only does the installation of Venetian blinds on windows affect the temperature and comfort of the room, but it also has a crucial effect on interior lighting. Limiting the penetration of direct solar radiation will reduce the natural illuminance intensity of the room. Hence, lighting is a significant aspect of the design of comfort building. Table 2 shows changes in the level of room lighting is affected by the installation of shading on the windows.

Table 2 The effect of the angle of the venetian blind on indoor illuminance level (lux) at the day (2 PM)

\begin{tabular}{ccccc}
\hline Slope & $\begin{array}{c}\text { Without } \\
\text { shading }\end{array}$ & $\begin{array}{c}\text { With } \\
\text { shading }\end{array}$ & Reduction & $\begin{array}{c}\text { Percentage } \\
(\%)\end{array}$ \\
\hline $90^{0}$ & 1.280 & 230 & 1.050 & 82 \\
$45^{0}$ & 1.300 & 600 & 700 & 54 \\
$0^{0}$ & 1.000 & 700 & 300 & 30 \\
\hline
\end{tabular}

The installation of shading in a vertical slat position (tightly closed) caused the interior lighting to be drastically reduced by $82 \%$ of 1,280 lux to 230 lux (Table 2). With the installation of shading on the windowpane, the room becomes darker. It happened due to the lack of natural lighting that enters the room. Therefore, the building cannot provide visual comfort for occupants. Based on SNI 03-6197, 2000 [48], the minimum lighting limit for having visual comfort in a building for doing activities is between 300 - 500 lux $[49,50]$. To ensure visual comfort without natural light sources, artificial lights should always be turned on, even during the day. The most reduction in lighting occurs in Case-3, where the shading slats are installed horizontally. In Case-3, solar radiation is still possible to enter the room so that the lighting level is only reduced by $30 \%$ compared to the prototype without shading. This decrease in natural lighting will decrease comfort or inefficiency in electrical energy consumption for active lighting systems.

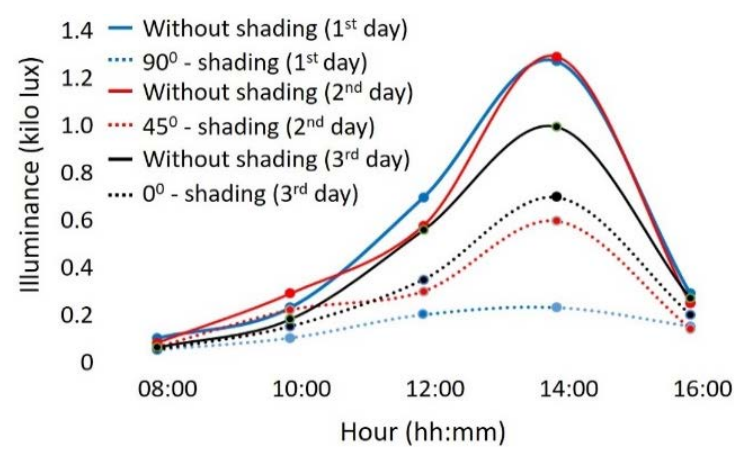

Fig.7 Comparison of indoor illuminance level for the two different cases 
Fig. 7 shows the changes in indoor illuminance values due to the shading installation with different shading slats angles. Measurements were made on different days for the three cases of slat angle slope; $90^{\circ}, 45^{\circ}$, and $0^{\circ}$, consecutively. The Case- 1 data measurement on the first day (blue line) showed a maximum decrease in the lighting value during the day by 1050 lux (82\%). For five measurement times, the average reduction in case- 1 was 374 lux or $61.7 \%$ lower than the prototype without shading (Fig. 6). Whereas in Case-3, where the shading slat is open (black line), the decrease in the average room lighting for the five measurement times was 124 lux, 25.4\% lower than buildings without shading. For all cases, the highest decrease occurred during the day was at $2 \mathrm{pm}$, where the intensity of solar radiation was the largest throughout the day. The decrease in lighting during the day influences the use of electric lights to ensure the visual comfort of residents.

Furthermore, analysis of advantages and disadvantages of the effect of the shading window on changes in temperature and lighting levels is carried out for the three determined slat angles. It is known that the installation of shading devices The installation of shading devices on windows creates two opposite impacts in terms of thermal and visual aspects. Thermally for tropical areas, shading devices can increase thermal comfort and energy consumption efficiency for air conditioning systems. However, in the visual comfort aspect, the installation of shading devices reduces natural lighting and forces occupants to turn on artificial lights to get visual comfort in the room.

Table 3 The effect of window shading devices in indoor air temperature and daylighting level during the day

\begin{tabular}{|c|c|c|c|c|c|c|}
\hline \multirow[t]{2}{*}{ Hour } & \multicolumn{3}{|c|}{$\begin{array}{l}\text { Indoor air Temperature } \\
\qquad\left({ }^{0} \mathrm{C}\right)\end{array}$} & \multicolumn{3}{|c|}{$\begin{array}{c}\text { Indoor daylighting } \\
\text { level (lux) }\end{array}$} \\
\hline & $T_{0}$ & $T_{1}$ & $\Delta T$ & $I_{0}$ & $I_{1}$ & $\Delta D L$ \\
\hline \multicolumn{7}{|c|}{ Case-1: $90^{0}$ (Shading slats are closed) } \\
\hline 10.00 & 31.98 & 30.97 & 1.02 & 230 & 100 & 130 \\
\hline 12.00 & 35.20 & 34.27 & 0.93 & 700 & 200 & 500 \\
\hline 14.00 & 35.53 & 34.80 & 0.73 & 1280 & 230 & 1050 \\
\hline \multicolumn{7}{|c|}{ Case-2: $45^{0}$ (Shading slats are partially closed) } \\
\hline 10.00 & 36.33 & 35.67 & 0.67 & 290 & 220 & 70 \\
\hline 12.00 & 36.35 & 35.35 & 1.00 & 580 & 300 & 280 \\
\hline 14.00 & 37.26 & 36.38 & 0.89 & 1300 & 600 & 700 \\
\hline \multicolumn{7}{|c|}{ Case-2: $0{ }^{0}$ (Shading slats are opened) } \\
\hline 10.00 & 36.33 & 35.67 & 0.67 & 180 & 150 & 30 \\
\hline 12.00 & 36.35 & 35.35 & 1.00 & 560 & 350 & 210 \\
\hline 14.00 & 37.02 & 36.10 & 0.92 & 1000 & 700 & 300 \\
\hline
\end{tabular}

Table 3 shows the effect of shading angle on changes in temperature and illuminance level for the hottest times of the day when the solar radiation intensity is maximum (10:00, 12:00 and 14:00
O'clock). Table 3 presents that the highest decrease in indoor air temperature occurs in case- 1 where the shading slats cover the entire surface of the window glass. During the day, positioning the shading slat to cover the entire surface of the window can be a suitable solution to make the building cooler. But on the contrary, totally covering the window glass surface with a shading device causes a significant decrease in daylight illuminance in the room. Reduction of direct solar radiation by shading device in case-1, makes the daylighting illuminance of the room lower than the minimum requirement of 300 lux [51].

By considering two opposite effects, the measurement data of case- 2 and case- 3 , presents better performance than case- 1 . Indoor air temperature in case- 2 and case-3 can be cooler than indoor temperature of the reference building without shading, with acceptable dayligth illuminance level for visual comofort. Therefore, to optimize the use of shading devices in the tropics, it is necessary to carry out a comprehensive analysis by comparing the thermal gains obtained with the lighting lost.

\section{CONCLUSION}

Installation of Venetian blinds as shading on building windows has a good impact on decreasing indoor temperature and increasing thermal comfort for occupants. Shading devices that cover the window will reduce the penetration of direct sunlight into the room. For tropical areas with hothumid characteristics, shading devices can be an alternative in minimizing unwanted thermal gain in the room during the day. A significant decrease in temperature can increase the comfort level of occupants in an unconditioned building or the energy efficiency for cooling systems in buildings. On the other hand, shading devices can reduce daylight illumination in the room and causes visual discomfort for occupants. In perfect shading slat closure, the level of lighting in the room cannot meet the requirements set out by building thermal regulations and standards. Thus, the artificial lights will still be turned on during the day if we use window shading. Using artificial lights during the day may cause inefficient energy consumption. Therefore, it is necessary to conduct an optimization study related to the operational strategy of window shading to a maximum reduction of the room temperature without increasing the energy consumption for the lighting system. The methodology and results of this study are expected to provide insight into the strategy of controlling the direct sunlight penetration into the room through the installation of window shading devices in tropical climates with hot-moist conditions. 


\section{ACKNOWLEDGEMENT}

The authors would like to thank Research and Community Service Institute (Lembaga Penelitian dan Pengabdian Masyarakat) Universitas Negeri Padang for funding this work with a contract number: 893/UN35.13/LT/2021.

\section{REFERENCES}

[1] Andargie MS, Touchie M, O’Brien W. A review of factors affecting occupant comfort in multi-unit residential buildings. Build Environ 2019; 160: 106182.

[2] Lapisa R, Karudin A, Martias, Krismadinata, Ambiyar Romani Z, Salagnac P. Effect of skylight-roof ratio on warehouse building energy balance and thermal-visual comfort in hot-humid climate area.

[3] Chen C-F, Yilmaz S, Pisello AL, De Simone M, Amy K, Tianzhen H, Karol B, Mateus V.B, Pei-Ling L,Yimin Z. The impacts of building characteristics, social psychological and cultural factors on indoor environment quality productivity belief. Build Environ 2020; 185: 107189.

[4] Al Horr Y, Arif M, Kaushik A, Mazroei A, Elsarrag E, Mishra S. Occupant productivity and indoor environment quality: A case of GSAS. Int J Sustain Built Environ 2017; 6: 476-490.

[5] Sattayakorn S, Ichinose M, Sasaki R. Clarifying thermal comfort of healthcare occupants in tropical region: A case of indoor environment in Thai hospitals. Energy Build 2017; 149: 45-57.

[6] Petidis I, Aryblia M, Daras T, Tsoutsos T. Energy saving and thermal comfort interventions based on occupants' needs: A students' residence building case. Energy Build 2018; 174: 347-364.

[7] Homod RZ, Almusaed A, Almssad A, Almssad A, Jaafar MK Goodarzi M, Sahari SM. Effect of different building envelope materials on thermal comfort and airconditioning energy savings: A case study in Basra city, Iraq. J Energy Storage 2021; 34: 101975.

[8] Lapisa R, Karudin A, Rizal F, Krismadinata, Nasruddin. Passive cooling strategies in roof design to improve the residential building thermal performance in tropical region. Asian J Civ Eng 2019; 20: 571-580.

[9] Limphitakphong N, Chaikatetham N, Khaimook T, Chavalparit O. Performance of air conditioning system in educational building for energy conservation. Int J 2019; 16: 177-182.
[10] Singer BC, Chan WR, Kim Y-S, Offermann FJ and Walker IS. Indoor air quality in California homes with code-required mechanical ventilation. Indoor Air 2020; 30: 885-899.

[11] Ni J, Bai X. A review of air conditioning energy performance in data centers. Renew Sustain Energy Rev 2017; 67: 625-640.

[12] Ciconkov R. Refrigerants: There is still no vision for sustainable solutions. Int $\mathrm{J}$ Refrig 2018; 86: 441-448.

[13] Lapisa R. The Effect of Building Geometric Shape and Orientation on Its Energy Performance in Various Climate Regions. Int J Geomate 2019; 16: 113-119.

[14] Lapisa R, Bozonnet E, Abadie MO, Salagnac P. Cool roof and ventilation efficiency as passive cooling strategies for commercial lowrise buildings - ground thermal inertia impact. Adv Build Energy Res 2013; 7: 192-208.

[15] Laghmich N, Romani Z, Lapisa R, Abdeslam D. The impact of internal gains on thermal stratification for public buildings. In: IOP Conference Series: Materials Science and Engineering. IOP Publishing, 2019, p. 042090.

[16] Lapisa R, Abadie M, Bozonnet E, Salagnac P. Numerical analysis of thermal stratification modelling effect on comfort for the case of a commercial low-rise building. In: The 13th International Conference on Indoor Air Quality and Climate. Hongkong: International Society of Indoor Air Quality and Climate (ISIAQ), 2014.

[17] Lapisa R, K Arwizet, Martias, Purwantono, Wakhinuddin, Suparno, Romani Z. Analysis of Thermal Effects of Roof Material on Indoor Temperature and Thermal Comfort. Int J Adv Sci Eng Inf Technol 2020; 10: 2068-2074.

[18] Arunraj E, Hemalatha G, Noroozinejad Farsangi E. A Novel Lightweight Phasechanging Cooling Roof Tile. Int J Eng 2021; 34: 1398-1406.

[19] Tukiran JM, Ariffin J, Ghani ANA. A study on the cooling effects of greening for improving the outdoor thermal environment in Penang, Malaysia. Int J 2017; 12: 62-70.

[20] Elqattan AA, Elrayies GM. Developing a novel solar-driven cool pavement to improve the urban microclimate. Sustain Cities Soc 2021; 64: 102554.

[21] Aruninta A, Kurazumi Y, Fukagawa K, Ishii J. The integration of human thermal comfort in an outdoor campus landscape in a tropical climate. Int J 2018; 14: 26-32.

[22] Amasyali K, El-Gohary NM. A review of data-driven building energy consumption prediction studies. Renew Sustain Energy Rev 2018; 81: 1192-1205. 
[23] Huang L, Krigsvoll G, Johansen F, Liu Y, Zhang $X$. Carbon emission of global construction sector. Renew Sustain Energy Rev 2018; 81: 1906-1916.

[24] Che WW, Tso CY, Sun L, Ip DYK, Lee H, Chao CYH, Lau AKH. Energy consumption, indoor thermal comfort and air quality in a commercial office with retrofitted heat, ventilation and air conditioning (HVAC) system. Energy Build 2019; 201: 202-215.

[25] McNeil MA, Karali N, Letschert V. Forecasting Indonesia's electricity load through 2030 and peak demand reductions from appliance and lighting efficiency. Energy Sustain Dev 2019; 49: 65-77.

[26] Ihm P, Nemri A, Krarti M. Estimation of lighting energy savings from daylighting. Build Environ 2009; 44: 509-514.

[27] Dolnikova E, Katunsky D. Visual Comfort Assessment in the Office: A Case Study. In: SGEM 2019 Conference Proceedings. 2019, pp. 597-604.

[28] Lapisa R, Bozonnet E, Salagnac P, Abadie MO. Optimized design of low-rise commercial buildings under various climates - Energy performance and passive cooling strategies. Build Environ 2018; 132: 83-95.

[29] García-Sanz-Calcedo J, Al-Kassir A, Yusaf T. Economic and environmental impact of energy saving in healthcare buildings. Appl Sci 2018; 8: 440.

[30] Amirkhani M, Garcia-Hansen V, Isoardi G, Allan A. An energy efficient lighting design strategy to enhance visual comfort in offices with windows. Energies 2017; 10: 1126.

[31] Brembilla E, Hopfe CJ, Mardaljevic J, Mylona A, Mantesi E. Balancing daylight and overheating in low-energy design using CIBSE improved weather files. Build Serv Eng Res Technol 2020; 41: 210-224.

[32] Evola G, Gullo F, Marletta L. The role of shading devices to improve thermal and visual comfort in existing glazed buildings. Energy Procedia 2017; 134: 346-355.

[33] Speroni A. Adaptive shading device for high performance building envelope.

[34] Evangelisti L, Guattari C, Asdrubali F, De Lieto VR. An experimental investigation of the thermal performance of a building solar shading device. J Build Eng 2020; 28: 101089.

[35] Alhuwayil WK, Abdul Mujeebu M, Algarny AMM. Impact of external shading strategy on energy performance of multi-story hotel building in hot-humid climate. Energy 2019; 169: 1166-1174.

[36] Choi S-J, Lee D-S, Jo J-H. Lighting and cooling energy assessment of multi-purpose control strategies for external movable shading devices by using shaded fraction. Energy Build 2017; 150: 328-338.

[37] Foroughi R, Asadi S, Khazaeli S. New Approach in Designing a Kinetic Window Shading Using Optimization Methods. J Archit Eng 2020; 26: 04020023.

[38] Shahdan MS, Ahmad SS, Hussin MA. External shading devices for energy efficient building. IOP Conf Ser Earth Environ Sci 2018; 117: 012034.

[39] Al Dakheel J, Tabet Aoul K. Building Applications, Opportunities and Challenges of Active Shading Systems: A State-of-the-Art Review. Energies 2017; 10: 1672.

[40] Strahler AN. The Koppen climate classification system. Phys Geogr 2nd Ed N Y John Willey 1963; 185-188.

[41] Karyono TH. Predicting Comfort Temperature in Indonesia, an Initial Step to Reduce Cooling Energy Consumption. Buildings 2015; 5: 802-813.

[42] Mulyadi R, Jamala N, Rahim R. An examination on daily horizontal illuminance data in Indonesia. 8th SENVAR 2nd MALAY Surabaya Indones.

[43] Szokolay S. Introduction to architectural science. Routledge, 2012.

[44] Li DHW, Lau CCS, Lam JC. A Study of 15 Sky Luminance Patterns against Hong Kong Data. Archit Sci Rev 2003; 46: 61-68.

[45] Mandala A, Santoso AR. Comparative Study of Daylighting Calculation Methods. In: SHS Web of Conferences. EDP Sciences, 2018, p. 06001.

[46] Bahia RT, Estur, Blanco, Soriano. Illuminance mapping of nighttime road environment using numanned aerial system. Int Arch Photogramm Remote Sens Spat Inf Sci.

[47] Kramer KM, Birney EC. Effect of light intensity on activity patterns of Patagonian leaf-eared mice, Phyllotis xanthopygus. J Mammal 2001; 82: 535-544.

[48] SNI 03-6197 IS. Energy Conservation in the Air Conditioning System in Buildings.

[49] Mardaljevic J. Climate-based daylight analysis for residential buildings. Impact Var Window Config Extern Obstructions Orientat Locat Useful Daylight Illuminance.

[50] Schüler M. Developing concepts for low energy buildings through a co-operation between architect and engineer.

[51] Nandi S, Sawkar S. Intensity of Artificial Lighting in Living Room and Study Area of Urban Residential Homes in Dharwad City. J Hum Ecol 2007; 21: 63-64.

Copyright (C) Int. J. of GEOMATE All rights reserved, including making copies unless permission is obtained from the copyright proprietors. 